Table 2

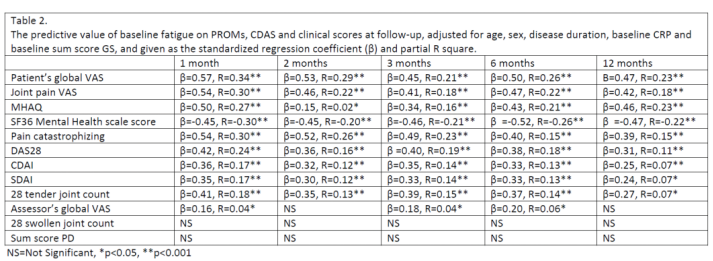

Disclosure of Interests: Hilde Berner Hammer Grant/research support from: AbbVie, Pfizer and Roche, Paid instructor for: AbbVie, Pfizer, UCB, Novartis, Roche, Speakers bureau: AbbVie, Pfizer, UCB, Novartis, Roche, Brigitte Michelsen Grant/research support from: Unrestricted grant: Novartis, Consultant for: Novartis, UCB, Sella Aarrestad Provan Consultant for: Novartis, Speakers bureau: Lilly, Till Uhlig Consultant for: Grünenthal, Novartis, Speakers bureau: Grünenthal, Novartis, Tore K. Kvien Grant/research support from: AbbVie, BMS, MSD, Pfizer, Roche and UCB., Consultant for: AbbVie, Biogen, BMS, Boehringer Ingelheim, Celgene, Celltrion, Eli Lilly, Hospira, MerckSerono, MSD, Novartis, Oktal, Orion Pharma, Pfizer, Roche, Sandoz, Sanofi, Mylan and UCB, Speakers bureau: AbbVie, Biogen, BMS, Boehringer Ingelheim, Celgene, Celltrion, Eli Lilly, Hospira, Merck-Serono, MSD, Novartis, Oktal, Orion Pharma, Pfizer, Roche, Sandoz, Sanofi and UCB DOI: 10.1136/annrheumdis-2019-eular.1538

\section{AB0258 POTENTIAL ROLE OF MEAN PLATELET VOLUME AND RED BLOOD CELL DISTRIBUTION WIDTH AS A BIOMARKER FOR CLINICAL AND SONOGRAPHIC ACTIVITY IN RHEUMATOID ARTHRITIS PATIENTS}

Waleed Hassan ${ }^{1}$, Mounir Elhanafi ${ }^{1}$, Refaat Eltanawy ${ }^{1}$, Rehab Shehab El-Din ${ }^{2}$. ${ }^{1}$ Benha University, Rheumatology and Rehabilitation, Benha, Egypt, ${ }^{2}$ Kafr elshikh general hospital, Rheumatology and Rehabilitation, Kafr elshikh, Egypt

Background: Red cell distribution width (RDW) reflects the variation in the circulating erythrocytes size (anisocytosis) that can increase in chronic inflammation due to ineffective erythropoiesis [1], while mean platelet volume (MPV) reveals the average size of platelets and may disclose its activation. Both are typically included in the complete blood count (CBC) and have been studied as a possible indicator of disease activity in many inflammatory conditions [2].

Objectives: This study aimed to assess the relationship between MPV and RDW levels and various rheumatoid arthritis (RA) clinical,laboratory and ultrasongraphic disease activity parameters in patients with recent onset RA before and after initiation of therapy.

Methods: We assessed MPV and RDW in blood samples obtained from 60 recent onset RA patients and 30 healthy controls at baseline and 4 months after initiation therapy with non-biological disease modifying antirheumatic drugs (DMARDS). Disease activity was calculated using the 28 joint counts (DAS28) and musculoskeletal ultrasound examination (MSUS) was performed at baseline and after 4 months using a 12-joint score (bilateral elbow, wrist, $2^{\text {nd }}$ metacarpophalangeal $(\mathrm{MCP}), 3$ rd MCP, knee, ankle) [2]; Erythrocyte sedimentation rate (ESR), C-reactive protein (CRP) levels, rheumatoid factor (RF) titre and anti-cyclic citrullinated peptide (anti-CCP) antibodies titre were measured and the health assessment questionnaire (HAQ) score was documented.

Results: Baseline RDW was significantly increased in RA (15.16 $\pm 3.63 \%)$ compared to its level in the healthy controls $(12.16 \pm 1.43 \%) \quad(p<0.001)$. While, there was no significant difference in MPV between RA and control groups $(10.92 \pm 2.02 \mathrm{fl}$ and $10.08 \pm 0.88 \mathrm{fl}$ respectively) $(p=0.2)$. In RA patients, baseline RDW significantly correlated with $\operatorname{CRP}(r=0.39, p<0.05)$, DAS28 $(r=0.47, p<0.05)$, grey scale (GS) $(r=0.53, p<0.05)$ and power Doppler (PD) $(r=0.56, p<0.001)$ synovitis scores. Also, RDW at 4 months follow up significantly correlated with the DAS28 $(r=0.42, p<0.05)$, GS score $(r=0.45, p<0.05)$. MPV showed no significant correlation with clinical, laboratory and ultrasonographic parameter of RA disease activity. Baseline RDW ( $p=0.02$ ) was shown to be comparable to ESR ( $p=0.03$ ) but less than CRP ( $p=0.001)$ at predicting PD synovitis score.

Conclusion: Rheumatoid arthritis patients have significantly increased RDW levels that remarkably correlated with clinical, laboratory and MSUS parameters of inflammations suggesting that it could be a useful marker to reflect RA disease activity. RDW could be a useful biomarker to predict treatment outcome in RA patient. In this regard, MPV had poor correlations.

\section{REFERENCES}

[1] Aksoy ŞN, Savaş E, Sucu M, Kisacik B, Kul S, Zengin O. Association between red cell distribution width and disease activity in patients with Behçet's disease. J Int Med Res. 2015 Dec;43(6):765-73.
[2] Tecer D, Sezgin M, Kanık A, İncel NA, Çimen ÖB, Biçer A, Şahin G. Can mean platelet volume and red blood cell distribution width show disease activity in rheumatoid arthritis?. Biomark Med. 2016 Sep; 10(9):967-74.

[3] Naredo E, Rodríguez M, Campos C, Rodríguez-Heredia JM, Medina JA, Giner E, et al. Validity, reproducibility, and responsiveness of a twelve-joint simplified power Doppler ultrasonographic assessment of joint inflammation in rheumatoid arthritis. Arthritis Rheum 2008;59(4):515-22.

Disclosure of Interests: None declared

DOI: 10.1136/annrheumdis-2019-eular.5809

\section{AB0259 FOUR COMORBIDITY INDEXES AMONG PATIENTS WITH RHEUMATOID ARTHRITIS}

Yun-Ju Huang ${ }^{1}$, Chang-Fu Kuo ${ }^{1}$, Jung-Sheng Chen ${ }^{2}$, Shue-Fen Luo ${ }^{1} .{ }^{1}$ Division of Rheumatology, Allergy and Immunology, Taoyuan City, Taiwan, Republic of China; ${ }^{2}$ Center fo big data analytics and statistics, Taoyuan City, Taiwan, Republic of China

Background: Previous studies have reported an increased risk of multiple comorbidities in people with RA therefore it is necessary to systematically quantify the comorbidity burden of these patients.[1] The comorbidity index is a tool developed under this concept and has multiple clinical and research uses.

Objectives: We compared four comorbidity indexes and mortality rate in patients with rheumatoid arthritis in Taiwan (Charlson Comorbidity Index (CCl), Elixhauser Comorbidity Index (ECl), Mutimorbidity index (MMI), Rheumatic Disease Comorbidity Index (RDCl))

Methods: All patients with rheumatoid arthritis diagnosed during 19982008 in Taiwan were identified using the Taiwan National Health Insurance Database and followed up to 31 Dec 2013. One-year mortality rate and 5-year mortality rate were compared using $\mathrm{CCl}, \mathrm{ECl}, \mathrm{MMI}$ and $\mathrm{RDCl}$. High risk group for each index was defined as around the top $20 \%$ patients. A discrimination analysis was performed to compare the predictive ability of the model against the base model using the change of Harrell's c-statistics and the Akaike information criterion (AIC).

Results: Among 24767 patients with rheumatoid arthritis, median age at diagnosis is 51 years old and female is $79.2 \%$. The one-year and 5 -year mortality rate (per 1000 people) is 41 vs. 177 in CCl, 43 vs. 135 in $\mathrm{ECl}, 43$ vs. 169 in $\mathrm{MMI}, 43$ vs. 159 in RDCl. (Low risk group vs. high risk group) The one-year and 5-year mortality rates all are higher in the high risk group compared with low risk group using four comorbidity indexes. The 5-year mortality rate rises up rapidly both in low risk group and high risk group using four comorbidity indexes. The discrimination analysis showed MMl predicted one-year and 5-year mortality best. (Harrell's c-statistics 0.796 in one-year mortality and 0.802 in 5-year mortality) $\mathrm{ECl}, \mathrm{MMI}$ and $\mathrm{RDCl}$ are all good at predicting mortality as well.

Conclusion: Our study showed mortality rate increased in patients after rheumatoid arthritis was diagnosed. All four comorbidity index score during diagnostic period predicted one-year and 5-year mortality rate well both in high risk and low risk group. Clinicians should screen different comorbidities, determine primary prevention and control disease activity to improve the functional status, quality of life and mortality of rheumatoid arthritis, especially in the patients with initial high comorbidity index scores.

\section{REFERENCE}

[1] Baillet, A., et al., Points to consider for reporting, screening for and preventing selected comorbidities in chronic inflammatory rheumatic diseases in daily practice: a EULAR initiative. Ann Rheum Dis, 2016. 75(6): p. 96573.

Table 1. 1-year and 5-year mortality analysis for four comorbidity indexes.

\begin{tabular}{lcc}
\hline & \multicolumn{2}{c}{ Mortality rate (per 1000 people) } \\
\hline Comorbidity indexes & 1-year & 5-year \\
\hline CCI & 3 & 41 \\
Low risk (0-1) & 23 & 177 \\
High Risk (>1) & & \\
ECl & 4 & 43 \\
Low risk (0-3) & 15 & 135 \\
High Risk (>3) & 4 & 43 \\
MMI & 19 & 169 \\
Low risk (0-1) & & \\
High Risk (>1) & 4 & 43 \\
RDCl & 18 & 159 \\
Low risk $(0-2)$ & \\
High Risk $(>2)$ &
\end{tabular}

High risk group for each index was defined as around the top $20 \%$ patients. 